The favourable results of two well-controlled trials of antifibrinolytic agents support the view that patients with duodenal and gastric lesions may have excessive local secretion of plasminogen activator causing release of plasmin that contributes to local haemorrhage. At this stage the gauntlet should be thrown to the physicians and surgeons to substantiate and amplify the claims; there must surely be fewer deaths if emergency surgery for uncontrolled upper gastrointestinal tract bleeding is avoided. At present we are still uncertain which gastric or duodenal conditions associated with haemorrhage may benefit most from antifibrinolytic treatment. We hope that, with the recent advances in endoscopy and radiology, suitable controlled trials will answer this question.

\footnotetext{
1 Todd, A S, fournal of Pathology and Bacteriology, 1959, 78, 281.

2 Astrup, T, Federation Proceedings, 1966, 25, 42.

3 McNicol, G P, et al, fournal of Urology, 1961, 86, 829.

${ }^{4}$ Nilsson, L, and Rybo, G, Acta Obstetrica Gynecologica Scandinavica, 1967, 46, 572.

${ }^{5}$ Callender, S T, Warner, G T, and Cope, E, British Medical fournal, 1970, 4, 214.

${ }^{6}$ Prentice, C R M, Thrombosis et Diathesis Haemorrhagica, 1975, 34, 634.

7 Cox, H T, Poller, L, and Thomson, J M, Lancet, 1967, 1, 1300.

${ }^{8}$ Cox, H T, Poller, L, and Thomson, J M, Gut, 1969, 10, 404.

9 Thomson, J M, Turner, L, and Poller, L, Annals of the Royal College of Surgeons of England, 1973, 53, 340.

${ }^{10}$ Thomson, J M, Thrombosis et Diathesis Haemorrhagica, 1974, 31, 291.

11 Nilsson, I M, et al, Thrombosis et Diathesis Haemorrhagica, 1975, 34, 409.

12 Cormack, F, et al, Lancet, 1973, 1, 1207.

${ }^{13}$ Biggs, J C, Hugh, T B, and Dodds, A J, Gut, 1976, 17, 729.
}

\section{Iodine and the thyroid}

The prime factor controlling thyroid function is thyrotrophin (TSH). Nevertheless, variations in the amount of iodine in the diet also affect thyroid function and may influence the development and course of thyroid diseases. Iodine deficiency is an important world health problem: no fewer than 200 million people are estimated to be affected by goitre, hypothyroidism, or endemic cretinism.

Whenever the iodine intake is consistently under $50 \mu \mathrm{g} /$ day thyroxine (T4) synthesis is reduced, with a compensatory increase in TSH secretion. This leads to increased trapping of iodide by the thyroid; a compensatory increase in the serum ratio of tri-iodothyronine to thyroxine (T3/T4); and goitre. Iodine depletion may also influence thyroid growth directly. ${ }^{1}$ Endemic goitre is associated with slightly reduced serum $\mathrm{T} 4$ and increased TSH; T3 concentrations are normal and are responsible for maintaining euthyroidism. ${ }^{2}$ Autonomous nodules (single or multiple) also occur more frequently in areas where goitre is endemic. Correction of the deficiency with iodide supplements not only abolishes endemic goitre and associated cretinism but also ultimately reduces the incidence of toxic nodular goitre.

An association exists between endemic goitre and thyroid follicular carcinoma, ${ }^{3}$ possibly resulting from prolonged exposure of the thyroid to increased TSH activity. Anaplastic carcinoma may be slightly more frequent and papillary carcinoma less common in areas of endemic iodine deficiency. In fact, papillary carcinoma is five times more common in Iceland (an iodine-rich area) than in North-east Scotland (an area of normal iodine intake $)^{4}$; it is inferred that dietary iodine has separate influences on the incidence of papillary carcinoma and follicular carcinoma.

The effects of a high intake of iodine are complex. There have been many reports of thyrotoxicosis after the administra- tion of iodide supplements (Jod Basedow effect) in areas of endemic iodine deficiency, one example of which occurred in Tasmania. ${ }^{5}$ Many affected patients had nodular goitres with some autonomy, and iodide probably unmasked latent hyperthyroidism. Other patients had thyroid-stimulating antibodies in the circulation, indicating subclinical Graves's disease. ${ }^{6}$ Similarly, patients with euthyroid "hot" nodules given iodide became overtly thyrotoxic, while even small doses (100-400 $\mu \mathrm{g}$ of potassium iodide daily) increased the serum $\mathrm{T} 4$ and $\mathrm{T} 3$ concentrations and made the clinical state worse. $^{7}$ Sustained hyperthyroidism was induced by giving $180 \mathrm{mg}$ potassium iodide a day to patients with nontoxic goitres in an area with adequate iodine intake; this was attributed to defective homoeostatic control mechanisms. ${ }^{8}$ Hyperthyroidism has also been described in patients with apparently normal thyroid glands given iodine-containing drugs or radiodiagnostic contrast media. ${ }^{9}$ Furthermore, patients who have been treated with antithyroid drugs show an increased relapse rate in their thyrotoxicosis if they increase their iodide intake. ${ }^{10}$

Conversely, iodide has a suppressive effect on the thyroid in various clinical conditions. Its acute inhibition of the release of thyroid hormone in thyrotoxicosis is well known, though this is short-lived; if administration of iodide is continued adaptive mechanisms may take over and the hyperthyroidism recur. Nevertheless, iodide given to patients who had been treated with radioiodine for Graves's disease induced frank myxoedema, indicating a sustained inhibition of the synthesis of thyroid hormone. ${ }^{11}$ Prolonged administration of iodide-for example, to asthmatics-may induce hypothyroidism and goitre, because of either the unmasking of defective organic iodination or the presence of subclinical Hashimoto's thyroiditis. ${ }^{12}$

Many of these effects have been induced by iodide given experimentally or therapeutically, but they suggest that a high iodine intake in a population may affect the pathophysiology and natural history of thyroid disease. This is borne out by further comparisons between Iceland and North-east Scotland. In Iceland most people have an unusually small thyroid gland which is exceptionally rich in iodin $\mathrm{e}^{13}$; serum TSH concentrations are lower and the response to exogenous TSH is enhanced ${ }^{14}$; hyperthyroidism is common. After subtotal thyroidectomy for thyrotoxicosis the prevalence of hypothyroidism is five times lower, but of recurrent hyperthyroidism five times higher than in North-east Scotland, ${ }^{13}$ probably because the high dietary iodine intake affects the functional capacity of the remnant. Clearly an excess of iodine seems undesirable; it may lead to increased prevalence of hyperthyroidism, as well as a predisposition to relapse after treatment with antithyroid drugs or subtotal thyroidectomy.

${ }^{1}$ Ingbar, S H, Mayo Clinic Proceedings, 1972, 47, 814.

2 Pharoah, P O D, et al, Clinical Endocrinology, 1973, 2, 193.

${ }^{3}$ Doniach, I, in Tumours of the Thyroid Gland. Ed D Smithers. Edinburgh, Livingstone, 1970.

4 Williams, E D, et al, Cancer, 1977, 39, 215

${ }^{5}$ Connolly, R J, Vidor, G I, and Stewart, J C, Lancet, 1970, 1, 500.

${ }^{6}$ Adams, D D, et al, fournal of Clinical Endocrinology and Metabolism, 1975, 41, 221

${ }^{7}$ Livadas, D P, et al, Clinical Endocrinology, 1977, 7, 121.

8 Vagenakis, A G, et al, New England fournal of Medicine, 1972, 287, 523.

${ }^{9}$ Savoie, J C, et al, Fournal of Clinical Endocrinology and Metabolism, 1975, 41, 685.

${ }^{10}$ Alexander, W D, et al, Lancet, 1965, 2, 866

11 Braverman, L E, Woeber, K A, and Ingbar, S H, New England fournal of Medicine, 1969, 281, 816.

${ }^{12}$ Hall, R, Turner-Warwick, M, and Doniach, D, Clinical and Experimental Immunology, 1966, 1, 285.

13 Sigurionsson, J, American fournal of Pathology, 1950, 26, 1103.

${ }^{14}$ Hedley, A J, et al, Clinical Endocrinology, 1977, 7, 377.

15 Thjodleifsson, B, et al, Clinical Endocrinology, 1977, 7, 367. 